\title{
Why and How Should We Integrate Biomarkers into Complex Trials? A Discussion on Paradigms and Clinical Research Strategies
}

\author{
Frauke Musial $^{\mathrm{a}}$ Scott Mist ${ }^{\mathrm{b}}$ Sara Warber ${ }^{\mathrm{c}}$ Mary Jo Kreitzer ${ }^{\mathrm{d}}$ \\ Cheryl Ritenbaugh ${ }^{\mathrm{e}}$ Christian Kessler ${ }^{f}$

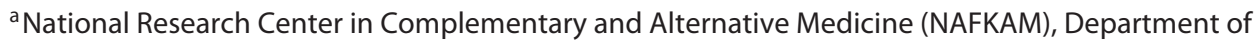 \\ Community Medicine, Faculty of Health Sciences, UiT The Arctic University of Norway, Tromsø, Norway; \\ ${ }^{b}$ School of Nursing, Oregon Health and Science University, Portland, OR, USA; 'Department of Family Medicine, \\ University of Michigan, Ann Arbor, MI, USA; ${ }^{d}$ Earl E. Bakken Center for Spirituality and Healing, University of \\ Minnesota, Minneapolis, MN, USA; ${ }^{e}$ Department of Family and Community Medicine, University of Arizona, \\ Tucson, AZ, USA; ${ }^{f}$ Department of Internal and Complementary Medicine, Immanuel Hospital and Institute of \\ Social Medicine, Epidemiology and Health Economics, Charité - University Medical Center, Berlin, Germany
}

\section{Keywords}

Complementary and alternative medicine $\cdot$ Biomarkers . Trial methodology · Complex interventions · Traditional medicine $\cdot$ Whole medical systems · Integrative medicine

\begin{abstract}
Background: Research in complementary and alternative medicine (CAM) encounters a variety of challenges, such as potentially synergistic, multimodal, and complex interventions which are often dependent on the relationship between practitioner and patient, on specific settings, and on patients' individual preferences, expectations, beliefs, and motivations. Moreover, patients seeking CAM care often suffer from chronic disease conditions, and multiple symptoms and/or pathologies. On the other hand, CAM interventions are often challenged as being solely dependent on subjective and nonspecific factors without biologically based mechanisms of action. If we agree that biomarkers as outcomes are important for the understanding of CAM interventions, a hypothesis- and strategy-driven process for the selection of the most appropriate biomarkers is needed. Methods: This paper presents the results of an expert panel on how to integrate biomarkers in whole system research of an interdisciplinary workshop on research methodology in CAM held in November 2012. Results: The following main CAM research challenges were identified: (a)
\end{abstract}

finding appropriate biomarkers, which are able to picture the complex pathophysiological pathways and likewise complex interventions under study; (b) integrating these biomarkers into clinical trials in CAM; and (c) identifying the biomarkers specific to the particular CAM intervention being applied. Conclusion: The paper provides a disease/condition/symptom- and intervention-driven strategy regarding how to identify the outcomes of interest and possible related biomarkers. The research approach presented here allows the selected biomarkers to be grounded in conventional physiology/pathophysiology as well as complementary and alternative concepts, including traditional systems of medicine. The goal is to provide researchers in the field with a framework on how to integrate biomarkers into complex trials.

(c) 2019 S. Karger AG, Basel

\section{Warum und wie sollten Biomarker in komplexe Studien integriert werden? Eine Diskussion über Paradigmen und klinische Forschungsstrategien}

\section{Schlüsselwörter}

Komplementärmedizin · Alternativmedizin · Biomarker · Klinische Studienmethoden · Komplexe Interventionen · Traditionelle Medizin · Holistische medizinische Systeme · Integrative Medizin

\section{KARGER}

(C) 2019 S. Karger AG, Basel 


\section{Zusammenfassung}

Hintergrund: Die Forschung im Bereich der Komplementär- und Alternativmedizin (CAM) muss sich mit einer Vielzahl von Herausforderungen auseinandersetzen. Dazu gehören potenziell synergistische, multimodale und komplexe Behandlungsmodelle, die häufig sehr von der Therapeut-Patient-Beziehung geprägt werden, ebenso wie die Tatsache, dass eine Behandlungssituation und Wahl sehr von den individuellen Präferenzen des Patienten, seinen Erwartungen, Überzeugungen und Motivationen abhängig sein kann. Darüber hinaus leiden Patienten, die eine CAM-Behandlung wünschen, häufig an chronischen Krankheitszuständen sowie komplizierten Symptombildern und/oder mehreren Pathologien zugleich. Eine weitere Herausforderung ist, dass CAM-Interventionen oftmals auf überlieferten Traditionen und Erfahrungswerten beruhen, ohne dass mögliche biologische Wirkmechanismen bekannt sind. Gerade aus diesem Grund kann es zielführend und interessant sein, Biomarker in eine wissenschaftliche Untersuchung zu integrieren, um so mehr über die potenziellen Wirkmechanismen von teilweise historisch sehr alten und traditionellen Therapien zu erfahren. Unter der Voraussetzung, dass Biomarker für das Verständnis von CAM-Interventionen nützlich sein können, ist ein hypothesen- und strategiegesteuerter Prozess für die Auswahl der am besten geeigneten Biomarker erforderlich. Methode: Es werden die Ergebnisse eines Expertenpanels zur Integration von Biomarkern vorgestellt. Das Panel war Teil eines interdisziplinären Workshops zu Forschungsmethoden in der CAM, der im November 2012 stattfand. Ergebnisse: Als die wichtigsten Herausforderungen wurden a) die Identifikation geeigneter Biomarker, die in der Lage sind, die komplexen pathophysiologischen Bedingungen chronischer Erkrankungen und ebenso komplexer Interventionen abzubilden, sowie b) die praktische Integration dieser Biomarker in klinische Studien im CAM-Bereich und c) die Selektion derjenigen Biomarker, die für die jeweilige CAM-Intervention spezifisch sind, identifiziert. Schlussfolgerung: Der Artikel schlägt eine an Krankheit/Zustand/ Symptombild/Intervention orientierte Strategie vor, mit der die wichtigsten Hauptzielgrössen für eine Studie und damit potenziell assoziierte und valide Biomarker identifiziert werden können. Das Ziel dieser Strategie ist es, klinischen Forschern ein System zur Einbindung von Biomarkern in komplexe klinische Studien anzubieten. Mit dem hier vorgestellten Forschungsansatz werden Biomarker auf Basis konventioneller Physiologie/Pathophysiologie ausgewählt, behalten aber gleichzeitig ihre Relevanz und Validität für die zumeist komplexen, komplementären und alternativen Therapien.

๑) 2019 S. Karger AG, Basel

\section{Introduction}

This paper is a consensus paper as one of the results of the workshop "Designing research aligned to the whole systems model of health, disease, and healing" as part of NAFKAM's 2012 Northern Lights Workshop series held in Sommarøy, Tromsø, Norway. The overall goal of the 2012 workshop was to define issues that need to be included in whole systems research and point to relevant methodological issues. The workshop started with the whole group of participants applying a World Cafe style brainstorming on topics and issues for whole systems model research designs. The potential role of biomarkers and whether and how they should/could be integrated in complex trials was identified as one of several relevant topics, and the group of co-authors was assigned as "expert" panel for this topic.

Within the expert panel, the participants began with a short brainstorming session on why biomarkers can be a useful outcome in complex trials. Taken from there, the expert panel developed a principal design template and discussed its operationalization with several, specific examples of increasing complexity. Since the group was small and rather homogenic in their opinions, the discussion was free and not formalized. The paper represents the consensus statement of the expert panel.

\section{The Problem: Evaluating the Impacts of Complex} Interventions

Research in complementary and alternative medicine (CAM) encounters a variety of challenges, such as potentially synergistic, multimodal, and complex interventions, aiming at symptom amelioration, and psychosocial and behavioral changes in the patient with long-term effects. Furthermore, these interventions are often dependent on the relationship between practitioner and patient, on specific medical settings, and on patients' preferences, expectations, beliefs, and motivations. Moreover, patients seeking CAM care often suffer from chronic diseases and multiple pathologies [1]. The challenges these complex and multifactorial conditions impose on clinical research design are particularly relevant for whole medical systems. Typical examples for whole medical systems are traditional medical systems such as Chinese medicine, Ayurveda, Kampo, Tibetan medicine, Unani-Tibb, Native American medicine, as well as homeopathy, anthroposophy, and the rapidly emerging field of integrative medicine. These whole systems not only include multiple treatment modalities, but also alternative diagnoses and patient-practitioner interactions, as well as techniques for changing the patients' (or in case of primary prevention, clients') behavior, all of which are frequently implemented in highly individualized fashions and in system-specif- 
ic settings [2-5]. Nonetheless, rigorous investigation of clinical effects in controlled clinical trials is possible [6$8]$, and even randomized clinical trials have been suggested [9].

Moreover, research in CAM frequently faces the challenges that treatments are not derived from conventional biological hypotheses and the therapies are implemented regardless of whether the "conventional" biological mechanisms, comparative effectiveness, component efficacy, or even safety aspects are documented in the research literature [10]. On the other hand, many of these interventions, in particular in whole medical systems [2], have been practiced for centuries or even millennia, so that at least an implicit empirical knowledge on clinical effectiveness and safety within certain cultural settings is available $[11,12]$.

All these preconditions, the complexity of the interventions and the treatment setting, the fact that many of the patients suffer from several chronic conditions or diseases, and the fact that there is generally no clear hypothesis on the biological mechanism of action, make the applicability of the gold standard in clinical research, the randomized controlled trial, particularly challenging [1, $2,10,13$ ] although, as we see it, not impossible. In the field of CAM, there has been a growing awareness that the development of appropriate methodological and statistical frameworks for the investigation of complex interventions is one of the key answers to the quest $[1,2,8,10]$, including a partial re-evaluation of the "outcomes" concept [13].

\section{Why Biomarkers as Outcomes for Complex}

Interventions?

Considering all the previously discussed challenges, why should we even attempt to utilize biomarkers as outcomes in complex trials? Treatment effects, measured by biomarkers, are usually considered a sign of specific efficacy. However, could and should we not be content if we are able to show the clinical effectiveness of CAM interventions to the benefit of the patient?

We believe that there are at least three good arguments for research strategies to also include biomarkers:

1 Pragmatism: CAM interventions in conventional medical care settings are often delivered in addition to conventional care or as being part of integrative medical care. Enhancing the understanding of complex CAM interventions with regard to the conventional biomedical model is likely to facilitate the integration of the various approaches and prevent possible undesirable interactions among different treatment modalities. The synergistic effect of a common basis of understanding would improve care, increase patient safety, and improve practitioner and patient satisfaction.
2 Epistemology/hermeneutics: many systems of traditional healing are based on theoretical models about health and disease, or even broader, the organization of life in general. Broadening the spectrum of outcomes in complex CAM trials from emotional/motivational, functional/behavioral to biological/physiological mechanisms may allow for a "cross-talk" between the traditional and "western" natural science models of health and disease with the overarching goal of a common understanding and a better approximation of "medical realities."

3 Strategic: even though we recognize that the currently acknowledged "biopsychosocial model" reaches substantially beyond the boundaries of the "biomedical model" of health and disease, we observe that much of the current medical research, also within scientific CAM contexts, is still being conducted along the tenets of the biomedical model. If the aim is to establish complex CAM interventions in a model of good patient care, demonstrated effects on biomarkers will increase the potential for integration of CAM interventions in the predominant models of contemporary medicine.

\section{What Frameworks Can Guide Biomarker Selection for Complex Interventions?}

If we agree that biomarkers as outcomes are important for the understanding of CAM interventions, a hypothesis- and strategy-driven process for the selection of the most appropriate biomarkers is needed. Most importantly, the chosen biomarkers should be valid to the indication/condition/syndrome studied. This is best achieved, if they are oriented towards the core subjective health complaint or symptom of the patient. Moreover, as Paterson et al. [13] consequently emphasize, outcomes which are appropriate for complex health interventions ideally are able to reflect changes and dynamics. In complex health interventions we often see that a treatment, even under strictly controlled conditions, shows its effects in the way a subject adapts to a challenge. As Paterson et al. [13] point out, a process is something that enables the individual to adapt to varying experiences. Therefore, while trying to design a trial and searching for the right outcome, we may be trying to quantify something like a "flexibility-stability" continuum. With regard to including biomarkers among the outcomes, this means that we have to be aware of whether we expect a treatment to show its effect in the magnitude of an outcome or by altering its variability.

Two biomarkers exemplifying this principle are body temperature and heart rate variability. A stable body temperature (thermoregulation) is a core requirement in endothermic animals (like mammals) and a mechanism that provides a stable environment for the chemical reac- 
tions in the body cells. Body temperature undergoes slight variations due to circadian rhythms and activity; it is a classic example for homeostatic regulation [14]. Consequently, deviances from the normothermic optimum, such as fever, are generally a sign of disease or, at least, a prodromal symptom. Heart rate, on the other hand, is a classic example for a physiological variable made for flexibility and adjustment. Heart rate varies with regard to physical (e.g., sport) or psychological (e.g., stress) challenges and supports behavioral actions needed in response to the external (e.g., climbing stairs) or internal (e.g., thoughts and emotions) environment. The loss of heart rate variability is generally a pathological sign of cardiovascular disease. Consequently, heart rate variability would be a classic example for a dynamic variable, where a desirable treatment outcome could be an increase in heart rate variability [15].

These two examples illustrate that changes in processes (e.g., heart rate variability) as well as levels (e.g., homeostatic body temperature) may be indicators of improved health. It is highly relevant to consider the nature of the underlying mechanism when choosing a biomarker. First, the biomarker should relate directly to the question (e.g., whether the mean or median of a measure or an index of variability is appropriate) and will to some degree impact the study design. However, the question of how sensitive the biomarker is to change will to a large extent drive the study sample size needed to detect an effect.

These conceptual issues may be further challenged when trying to integrate biomarkers into complex interventional trials, since biomarkers are usually identified and selected on the basis of a clear, biological hypothesis investigated in a design which allows for the application of Wilhelm Wundt's (1832-1920) fundamental "principle of isolated variation" in experimentation (e.g., cited in Krauth [16]). The principle of isolated variation requires that the treatment groups are varied according to only one particular variable, which can be expected to exert an effect on the dependent or outcome variable. All other sources of variation must remain constant. The classical pharmacological randomized controlled trial is a typical example in that it only varies the content of the active drug against a placebo. The application of the "principle of isolated variation" is mandatory when biological mechanisms or the efficacy of a specific component of the therapy (component efficacy) of a treatment are to be studied (see also Fønnebø et al. [10]).

If the aim is to investigate the conventional biological underpinnings of CAM interventions, biomarkers are mandatory. With regard to biomarkers and the "principle of isolated variation," complex trials in the CAM field struggle with two major challenges:

(a) The mechanisms of action of the intervention are commonly unclear, and the explanatory models are rare- ly grounded in conventional physiology/pathophysiology. Therefore, it is often difficult to decide which variation of the experimental or treatment conditions is being isolated, and often several variables unavoidably change simultaneously. Consequently, biomarkers may also vary in uncontrolled ways in several of the treatment conditions. This can make the study results difficult to interpret.

(b) The CAM interventions are complex and often address several aspects of the patient and his or her symptoms, which from an understanding of the (e.g., organ-) specific conventional pathophysiology may be seen as unrelated to the disease or at least only relevant at the second or third level. However, these (cumulated) second- or third-level effects may actually have an impact on the specific pathophysiology, but the impact may show itself on a different, likely a longer, time line.

In the light of the complexity of the problem, can we integrate biomarkers into these multidimensional trials, and is there a need to do so? The answer to both questions is clearly "yes" $[2,13]$, and there has been an explicit call for "objective change indicators" which should preferably be biomarkers [13].

\section{Methods}

A Critical Reflection on the Use of Biomarkers and a "Caveat"

Even though this group of authors favors or is at least supportive to the concept of the use of biomarkers, we are well aware that a wrongly selected biomarker will not add to our understanding of mechanisms of effect of an intervention, quite the opposite. Since biomarkers are often seen as making study outcomes more credible and they are therefore "fashionable," it is also fundamental that the biomarkers used are in fact valid for (i) the symptom pattern and (ii) the intervention.

It is tempting to choose biomarkers which are convenient or readily available. A good example is the biomarker "salivary cortisol" which has often been utilized when stress reduction was suspected to play a role. However, salivary cortisol as a hormonal measure is a very dynamic stress marker, vulnerable to many different factors that play specific roles in patients, such as medications, comorbidities, and everyday stressors [17-19]. Therefore, salivary cortisol is not particularly suitable to detect long-term effects. It can, however, be used validly in standardized subexperiments, where a dynamic response is systematically evoked and where salivary cortisol is a well-established marker for the stress response [20,21] (see example 4).

It is exactly for these reasons that the biomarker expert panel was established at the Northern Lights workshop "Designing research aligned to the whole systems model of health, disease, and healing." The research strategy developed and suggested here intends to guide researchers in their selection of biomarkers, in order to avoid designs, where the chosen biomarker is not valid for the study. Such a situation is, at best, a waste of resources but can also, depending on the nature of the biomarker, set the study participants at risk, without adding useful information to the understanding of the mechanisms of effect and should be avoided. 
Strategies for the Selection of Specific Biomarkers in Complex

Clinical Trials

The central question is: how can biomarkers be selected strategically so that the likelihood that they are valid for the intervention and the design is maximized? The challenge can be addressed through the implementation of two general principles which refer (a) to the process of selecting the appropriate biomarkers and (b) the application of small "subexperiments" embedded within complex trials.

(a) The selection of biomarkers should be driven by the physiological system where the treatment-induced change can be expected, such as the CNS, the autonomic nervous system, the immune system, etc. Moreover, the level where the change is to be expected needs to be taken into account (e.g., for the CNS: at the level of the brain or below?) [22, 23]. The most rational guidance is provided by the relevant symptoms of the patient. If this is, for example, pain, then a pain-related biomarker would be appropriate.

(b) "Subexperiments" or challenges to the system are needed when complex interventions cannot be expected to alter biomarkers at a resting level/state but may alter the physiological response to psychophysiological challenge (e.g., mental stress, physical activity). In these subexperiments, specific challenges to the physiological system in focus, e.g. a stress test, are applied, and the change in response to the challenge, meaning an evoked response (e.g., change in heart rate variability), is measured as outcome (see also Fig. 4 below).

In the following section, we suggest a generalized trial design which provides a rational guideline for the selection of biomarkers, taking into account the challenges and frameworks identified above. Furthermore, we provide three different virtual trial examples to serve as examples for the application of the template, with different indications (low back pain, esophageal reflux disease, breast cancer survivors) and different complex interventions (traditional Chinese medicine, TCM, Ayurveda, and integrative care).

\section{Results}

\section{A Trial Design Template for a Strategic Biomarker \\ Selection}

Usually in a trial, the study participants are selected according to a health condition or disease by a diagnosis that is operationalized by inclusion and exclusion criteria. From here, either all or a selected subgroup of patients will receive a CAM treatment. The CAM treatment usually also has (i) its own definition of health and disease and (ii) its own theory of pathodynamics. Consequently, a second set of selection (inclusion and exclusion) criteria according to the premises of the whole medical system or other complex intervention may or may not be implemented. Figure 1 describes this process.

In the first step, the key symptom/variable which is expected to be addressed by the intervention needs to be identified, and an appropriate outcome measure as operationalized for this symptom/variable needs to be selected. This may often be a self-report outcome. Self-reports are of immense importance even though this paper focuses on biomarkers, because self-reports provide a

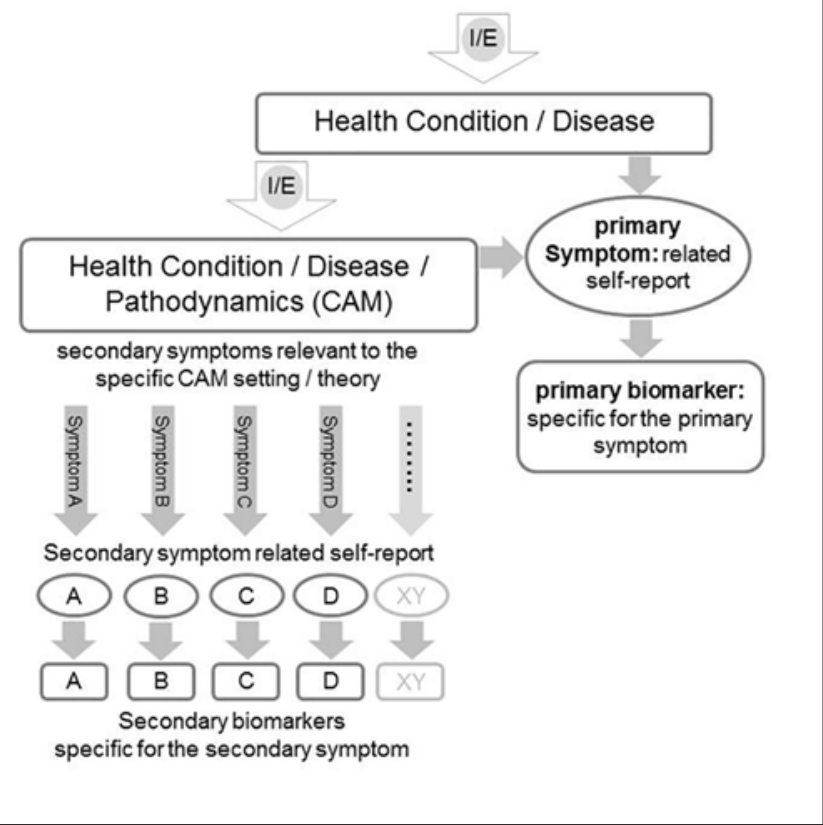

Fig. 1. Trial design template for the selection of suitable biomarkers. The biomarker selection is symptom driven. The primary biomarker is closely related to the primary symptom of the health condition or disease, while the secondary biomarker is closely related to a secondary symptom $(\mathrm{A}, \mathrm{B}, \mathrm{C}, \ldots \mathrm{XY})$, which is derived from the CAM-defined pathodynamics. I/E, inclusion/exclusion criteria.

measure for the most relevant aspect of any trial: they represent a measure of suffering, the outcome with the highest relevance for the patients and thus for the whole trial! A common example would be perceived pain as the key symptom and the visual analogue scale as its operationalization for measurement (see example TCM, Fig. 2). It is assumed that any type of successful intervention should be able to induce symptom relief.

The next step is to identify a biomarker, which is as closely related to the selected main symptom and/or self-report as possible. This biomarker will be the main or primary biomarker for the trial. For pain, this could for example be a neurophysiological measure taken from the quantitative sensory testing system (QST). QST includes a series of tests applying challenges in the form of controlled pain stimuli to the pain-processing system [22, 24-26] (see example TCM, Fig. 2). If the trial resulted in a change of the subjective measure and the primary biomarker, then this would document a health condition-/disease-related specific effect of the treatment.

However, every intervention that somehow addresses the main symptom is likely to also influence the related biomarker. For many of the purposes that biomarkers are 
Fig. 2. Example from a traditional Chinese medicine (TCM) trial on chronic low back pain. The primary biomarker is quantitative sensory testing which is a neurophysiological pain marker and thus closely related to the primary symptom back pain, measured by the pain rating. According to TCM theory, sleep quality is a relevant symptom related to chronic low back pain. Therefore, sleep quality is the secondary symptom relevant for TCM theory and measured with the Pittsburgh Sleep Quality Index. The appropriate secondary biomarker for sleep quality is the sleep EEG.

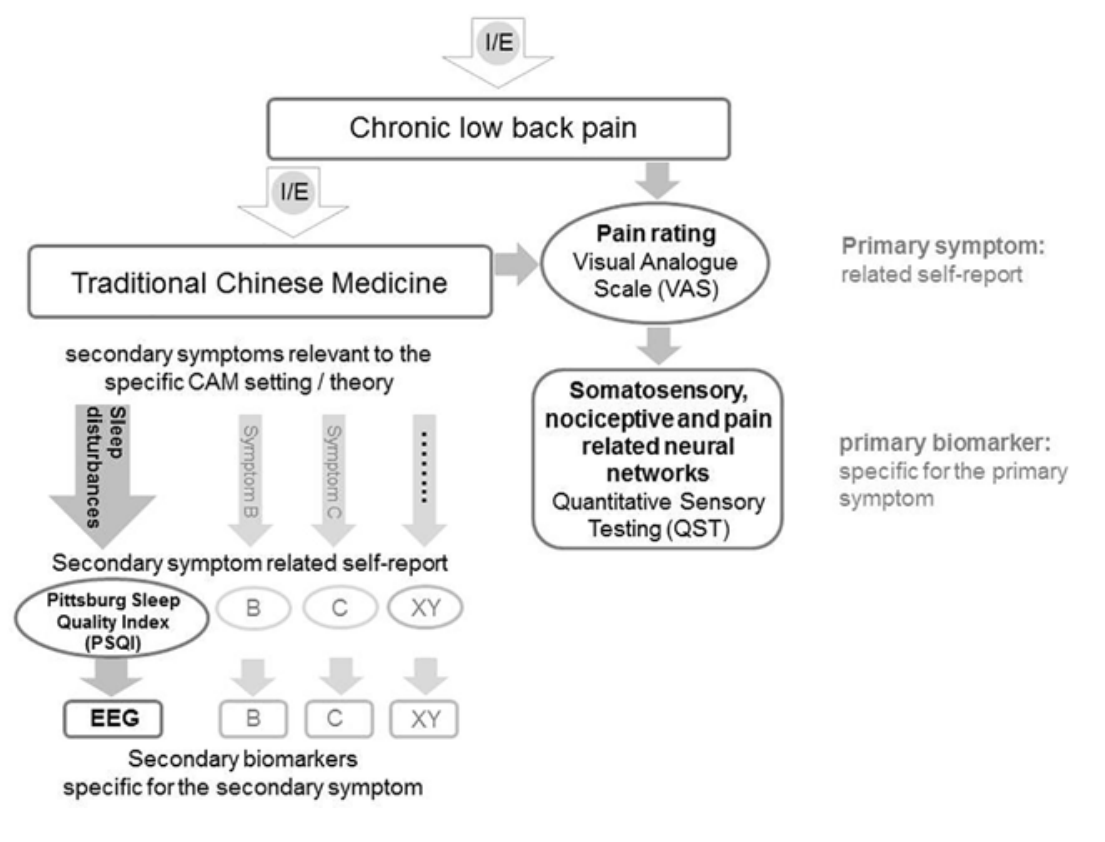

integrated into complex trials, this would be sufficient. Nonetheless, in order to identify specific intervention-related mechanisms of action, it may make sense to select other, additional biomarkers, which are less related to the main or core symptom, but more closely related to other aspects of the intervention. In order to be as specific to the intervention as possible, other symptoms, which are of relevance for the particular intervention, need to be identified. This is of major relevance in all whole medical systems trials, as the whole system interventions as a general rule address symptom complexes. One or more of these additional symptoms need to be identified. In our TCM example (Fig. 2), this is sleep disturbance, and consequently, the most appropriate biomarker for this symptom needs to be identified, which in this case could be a sleep EEG. We advocate that this additional symptom and biomarker should also be associated with a validated self-report measure.

As mentioned above, a theoretical example from a TCM trial on low back pain illustrates this strategy well (Fig. 2). Patients with low back pain are identified, and a selected subgroup is subjected to a complex TCM intervention. The visual analogue scale is chosen as subjective measure for the most relevant symptom, pain. Since the QST provides a biomarker directly targeting the painprocessing pathways and networks, it is a commonly utilized biomarker for pain-related interventions [22, 2426]. In TCM theory, a TCM diagnosis for the pain syndrome could be associated with sleep disturbances, therefore sleep disturbances are a second TCM-related symptom. In addition to a validated self-report, such as the Pittsburgh Sleep Quality Index [27], sleep quality could be assessed by EEG in a sleep laboratory. Consequently, if the TCM intervention reduces pain and shows a related pattern in the QST measures, then this outcome supports a specific effect on the pain-processing networks through the TCM intervention. If, in addition, the sleep EEG and Pittsburgh Sleep Quality Index are also indicative of a better sleep quality, then this result shows a pattern, which can be directly related to TCM theory. If the design was such that the TCM intervention was compared with other active conditions, which likewise reduced pain and related QST measures, but only the TCM interventions showed an effect on sleep disturbance or demonstrated the largest effect independent of pain score change, then this could be interpreted as a specific effect of the TCM intervention.

Our next hypothetical example (Fig. 3) illustrates the principle of a trial on gastroesophageal reflux disease (GERD), treated with a complex Ayurvedic intervention. After selecting subjects according to conventional criteria for GERD, a subgroup of patients suffering from $\mathrm{Am}$ la-Pitta according to Ayurvedic diagnosis could be further selected [26]. The main symptom in both the conventional and the Ayurvedic disease entity is heartburn (due to acid reflux), which can be measured by esophageal $\mathrm{pH}$ monitoring. Therefore, the related biomarker could be the determination of esophageal $\mathrm{pH}$ with an esophageal sensor monitoring $\mathrm{pH}$ using a $\mathrm{pH}$ catheter. The esophageal $\mathrm{pH}$ monitoring is also a good example for the earlier discussed principle that disease is often characterized by the loss of flexibility and that a healing 
Fig. 3. Gastroesophageal reflux disease and Ayurveda. The main symptom is heartburn which is measured by a symptom checklist and its impact on the quality of life, measured by the QOLRAD. Closely related to the main symptom is the esophageal $\mathrm{pH}$ as a biomarker. In addition, the Ayurvedic Amla-Pitta syndrome may also include a disposition for irritable bowel syndrome with diarrhea (IBS-D), and a tendency for aggressive behavior. Therefore, gastrointestinal (GI) transit and salivary testosterone were selected as secondary biomarkers. $\mathrm{I} / \mathrm{E}$, inclusion/exclusion criteria; AQ, aggression questionnaire.

Fig. 4. A multimodal complex treatment program for breast cancer survivors. The stress interview (Trier Social Stress Test, TSST) is a good example of a "subexperiment" or a challenge to the system in question embedded in a larger trial. I/E, inclusion/exclusion criteria; NK, natural killer; $\mathrm{HRV}$, heart rate variability.
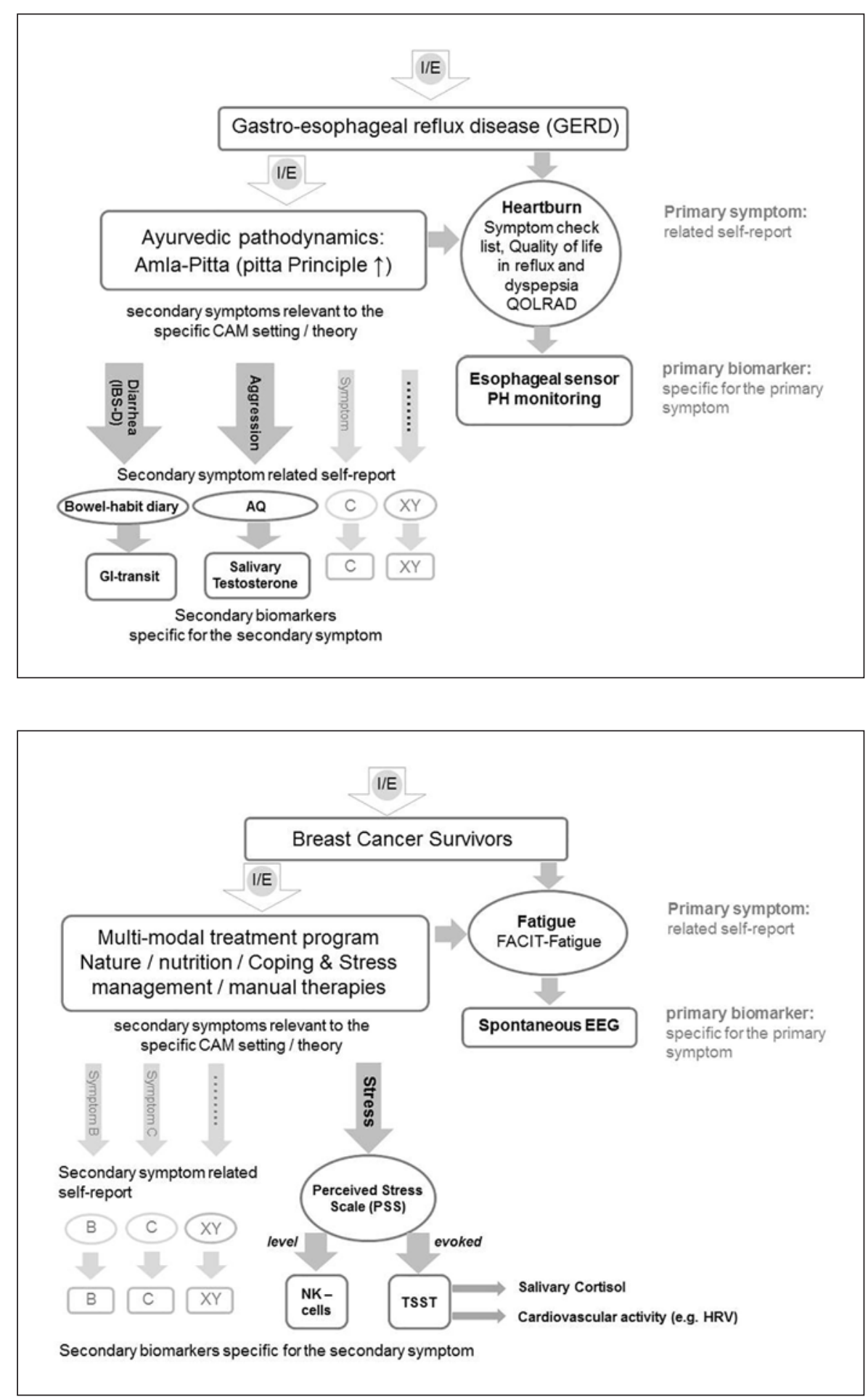

process may be shown in an increased flexibility after treatment. The subjective impact on the patients' life and their suffering can be measured with a variety of instruments [28-30]. The example here includes the reduction in quality of life specifically related to gastrointestinal reflux disease, measured with the QOLRAD [31]. In addition, the Ayurvedic Amla-Pitta syndrome may also include a disposition for irritable bowel syndrome with di- arrhea (IBS-D), and a tendency for aggressive behavior. Consequently, gastrointestinal transit and salivary testosterone were selected as additional biomarkers [32, 33], specifically chosen for the Ayurvedic theory and intervention. A bowel habit patient diary can be used as self-report measure for gastrointestinal transit and the aggression questionnaire as subjective measure for aggression $[34,35]$. 
As in our TCM example, a relief of heartburn together with an increase in esophageal $\mathrm{pH}$ would indicate a treatment effect on GERD. If this effect were associated with a reduced tendency for IBS-D and normalized gastrointestinal transit, as well as a reduced tendency for aggressive behavior and normalized salivary testosterone, and this pattern of effects would not show in other active control conditions, then this result would clearly relate back to the particularities of the Ayurvedic treatment and theory.

Our last example constructs a trial of a multimodal complex treatment program for breast cancer survivors (Fig. 4). The main symptom, which should be addressed by this treatment program, is fatigue. Therefore, the spontaneous EEG could be selected as the appropriate biomarker in order to indicate the CNS correlates of fatigue, namely increased slow wave activity [36-40]. The FACIT fatigue scale provides a reliable, functional measure of fatigue $[41,42]$. In addition, a major component of the multimodal treatment program focuses on stress and stress management under the assumption that the diagnosis of a potentially life-threatening disease and the subsequent therapy, often including surgery and chemotherapy, are major stressors. Of course, to measure stress, many selfreport instruments are available and should be carefully selected and applied. In our example, the Perceived Stress Scale, one of the many well-established and valid instruments, is chosen [43,44]. Moreover, here stress is seen as a variable that reflects a certain level (stress level) and would thus be a static condition, but which can also be seen as a dynamic event, the stress response to a challenge. Natural killer cells could be selected as a suitable biomarker for the measurement of stress level $[45,46]$. As for the measurement of the stress response, a stress interview, the Trier Social Stress Test [47], could be administered and skin conductance, salivary cortisol response, and other cardiovascular measures (e.g., heart rate response) measured $[15,20,21]$. Thus, the stress interview is a good example of a "subexperiment" embedded in a trial [47].

\section{Discussion/Conclusion}

We hope that the suggested strategies will assist other researchers in selecting biomarkers that are meaningful and valid for the interventions studied. As complex as the challenge is, these authors are convinced that a hypothesis- and symptom-driven framework is the most promising with regard to the validity of the selected outcomes. Nonetheless, integrating biomarkers in complex CAM trials is logistically challenging, tedious, time consuming, and costly.

Why should we do it? Research on CAM struggles with the fact that complex interventions have often been ap- plied over centuries or even millennia, and the clinical effectiveness of some is known and is sometimes even striking. However, there is rarely a good understanding (at least from the perspectives of conventional hermeneutics) as to why they work. Why is that so important?

It is widely accepted in the CAM field that a profound knowledge of the clinical effectiveness and the relevant context factors of these complex interventions is required in order to design patient-centered care models that are accepted by the global medical community and health care stakeholders. However, if we want to improve CAM interventions and tailor them around the complexity of the individual patient's needs, knowledge of the physiology involved in these interventions is mandatory. Moreover, this approach may be a valuable research tool in the attempt to analyze complex and whole medical systems as they currently exist.

We are well aware that others have previously made useful and explicit statements in relation to the integration of meaningful biomarkers into clinical trials $[2,10$, 13]. We wished to continue and extend this discussion in order to provide strategies on how this can be done most appropriately, guided both by the symptom pattern and the particularities of the CAM intervention chosen.

\section{Acknowledgments}

The Northern Lights Workshop in Sommarøy, 2012, was supported by a grant from the faculty of health sciences, UiT, The Arctic University of Norway, Tromsø, Norway. We are thankful to Åsa Sohlen for indispensable technical support.

\section{Disclosure Statement}

The authors declare that there are no competing interests.

\section{Author Contributions}

This paper is the result of a workshop which was part of NAFKAM's 2012 Northern Lights Workshop in Sommarøy, Tromsø, Norway. Therefore, all authors were involved in the development of the methodology and the concepts presented, and in the drafting of the overall paper outline. F.M. and S.M. developed the outline of the workshop. C.K. provided the conceptualization of the graphs. S.M., C.K., and S.W. provided specifics for the examples. All authors revised the manuscript carefully and approved the final version of the paper. 


\section{References}

1 MacPherson H, Peters D, Zollman C. Closing the evidence gap in integrative medicine. BMJ. 2009 Sep 1;339:b3335.

2 Ritenbaugh C, Aickin M, Bradley R, Caspi O, Grimsgaard S, Musial F. Whole systems research becomes real: new results and next steps. J Altern Complement Med. 2010 Jan; 16(1):131-7.

3 Kessler C, Michalsen A. The role of whole medical systems in global medicine. Forsch Komplement Med. 2012;19(2):65-6.

4 Kessler CS, Dhiman KS, Kumar A, Ostermann T, Gupta S, Morandi A, et al. Effectiveness of an Ayurveda treatment approach in knee osteoarthritis - a randomized controlled trial. Osteoarthritis Cartilage. 2018 May;26(5):620-30.

5 Kessler CS, Morandi A, Kumar A, Dhiman KS, Gupta S, Icke K, et al. Reliability of Ayurvedic Diagnosis for Knee Osteoarthritis Patients: A Nested Diagnostic Study Within a Randomized Controlled Trial. J Altern Complement Med. 2019 Jan;acm.2018.0273.

6 Furst DE, Venkatraman MM, McGann M, Manohar PR, Booth-LaForce C, Sarin R, et al. Double-blind, randomized, controlled, pilot study comparing classic ayurvedic medicine, methotrexate, and their combination in rheumatoid arthritis. J Clin Rheumatol. 2011 Jun;17(4 Suppl 1):185-92.

7 Furst DE, Venkatraman MM, Krishna Swamy BG, McGann M, Booth-Laforce C, Ram Manohar P, et al. Well controlled, doubleblind, placebo-controlled trials of classical Ayurvedic treatment are possible in rheumatoid arthritis. Ann Rheum Dis. 2011 Feb; 70(2):392-3.

8 Witt CM, Michalsen A, Roll S, Morandi A, Gupta S, Rosenberg M, et al. Comparative effectiveness of a complex Ayurvedic treatment and conventional standard care in osteoarthritis of the knee-study protocol for a randomized controlled trial. Trials. 2013 May;14(1):149.

9 Ernst E, Furst DE. A blueprint for placebocontrolled double-blind studies of complex, individualized interventions. Focus Altern Complement Ther. 2011;16(1):49-50.

10 Fønnebø V, Grimsgaard S, Walach H, Ritenbaugh C, Norheim AJ, MacPherson H, et al. Researching complementary and alternative treatments - the gatekeepers are not at home. BMC Med Res Methodol. 2007 Feb; 7(1):7.

11 World Health Organization (WHO). WHO traditional medicine strategy. Geneve: World Health Organization; 2002.

12 World Health Organization (WHO). Traditional medicine. Report by the secretariat. A 56/18. Geneva: World Health Organization; 2003.

13 Paterson C, Baarts C, Launsø L, Verhoef MJ Evaluating complex health interventions: a critical analysis of the 'outcomes' concept. BMC Complement Altern Med. 2009 Jun; 9(1): 18 .
14 Breedlove SM, Rosenzweig MR, Watson NV. Chapter 13: homeostasis: active regulation of internal states. In: Breedlove SM, Watson $\mathrm{NV}$, editors. Biological psychology. An introduction to behavioral, cognitive, and clinical neuroscience. 5th ed. Sunderland: Sinauer Associates; 2007. p. 388-93.

15 Thayer JF, Ahs F, Fredrikson M, Sollers JJ 3rd, Wager TD. A meta-analysis of heart rate variability and neuroimaging studies: implications for heart rate variability as a marker of stress and health. Neurosci Biobehav Rev. 2012 Feb;36(2):747-56.

16 Krauth J (Huston JP, editor). Experimental Design. A handbook and dictionary for medical and behavioral research. Techniques in the behavioral and neural sciences. Volume 15. Amsterdam: Elsevier; 2000.

17 Granger DA, Hibel LC, Fortunato CK, Kapelewski $\mathrm{CH}$. Medication effects on salivary cortisol: tactics and strategy to minimize impact in behavioral and developmental science. Psychoneuroendocrinology. 2009 Nov;34(10): 1437-48.

18 Hellhammer DH, Wüst S, Kudielka BM. Salivary cortisol as a biomarker in stress research. Psychoneuroendocrinology. 2009 Feb;34(2):163-71.

19 Kudielka BM, Hellhammer DH, Wüst S. Why do we respond so differently? Reviewing determinants of human salivary cortisol responses to challenge. Psychoneuroendocrinology. 2009 Jan;34(1):2-18.

20 Campbell J, Ehlert U. Acute psychosocial stress: does the emotional stress response correspond with physiological responses? Psychoneuroendocrinology. 2012 Aug; 37(8):1111-34.

21 Kudielka BM, Wüst S. Human models in acute and chronic stress: assessing determinants of individual hypothalamus-pituitaryadrenal axis activity and reactivity. Stress. 2010 Jan;13(1):1-14.

22 Musial F, Spohn D, Rolke R. Naturopathic reflex therapies for the treatment of chronic back and neck pain - Part 1: neurobiological foundations. Forsch Komplement Med. 2013;20(3):219-24.

23 Musial F, Michalsen A, Dobos G. Functional chronic pain syndromes and naturopathic treatments: neurobiological foundations. Forsch Komplement Med. 2008 Apr; 15(2): 97-103.

24 Rolke R, Baron R, Maier C, Tölle TR, Treede $\mathrm{RD}$, Beyer A, et al. Quantitative sensory testing in the German Research Network on Neuropathic Pain (DFNS): standardized protocol and reference values. Pain. 2006 Aug;123(3):231-43.

25 Rolke R, Magerl W, Campbell KA, Schalber C, Caspari S, Birklein F, et al. Quantitative sensory testing: a comprehensive protocol for clinical trials. Eur J Pain. 2006 Jan;10(1): 77-88.

26 Spohn D, Musial F, Rolke R. Naturopathic reflex therapies for the treatment of chronic pain - Part 2: quantitative sensory testing as a translational tool. Forsch Komplement Med. 2013;20(3):225-30.
27 Buysse DJ, Reynolds CF 3rd, Monk TH, Berman SR, Kupfer DJ. The Pittsburgh Sleep Quality Index: a new instrument for psychiatric practice and research. Psychiatry Res. 1989 May;28(2):193-213.

28 Murthy S. Madhava Nidanam (Roga Viniscaya) of Mahavakara. A Treatise On Ayurveda. 51. Reprint. Varanasi: Chaukambha Orientalia; 2001

29 Shaw MJ, Talley NJ, Beebe TJ, Rockwood T, Carlsson R, Adlis S, et al. Initial validation of a diagnostic questionnaire for gastroesophageal reflux disease. Am J Gastroenterol. 2001 Jan;96(1):52-7.

30 Wahlqvist $\mathrm{P}$, Guyatt GH, Armstrong D, Degl'innocenti A, Heels-Ansdell D, El-Dika S, et al. The Work Productivity and Activity Impairment Questionnaire for Patients with Gastroesophageal Reflux Disease (WPAIGERD): responsiveness to change and English language validation. Pharmacoeconomics. 2007;25(5):385-96.

31 Wiklund IK, Junghard O, Grace E, Talley NJ, Kamm M, Veldhuyzen van Zanten S, et al. Quality of life in reflux and dyspepsia patients. Psychometric documentation of a new disease-specific questionnaire (QOLRAD). Eur J Surg Suppl. 1998;(583):41-9.

32 Carré JM, Campbell JA, Lozoya E, Goetz SM, Welker KM. Changes in testosterone mediate the effect of winning on subsequent aggressive behaviour. Psychoneuroendocrinology. 2013 Oct;38(10):2034-41.

33 Carré JM, McCormick CM. Aggressive behavior and change in salivary testosterone concentrations predict willingness to engage in a competitive task. Horm Behav. 2008 Aug;54(3):403-9.

34 Buss AH, Perry M. The aggression questionnaire. J Pers Soc Psychol. 1992 Sep;63(3): 452-9.

35 O'Connor DB, Archer J, Wu FW. Measuring aggression: self-reports, partner reports, and responses to provoking scenarios. Aggress Behav. 2001;27:29-101.

36 Tanaka M, Shigihara Y, Funakura M, Kanai E, Watanabe Y. Fatigue-associated alterations of cognitive function and electroencephalographic power densities. PLoS One. 2012;7(4):e34774.

37 Tanaka M, Shigihara Y, Ishii A, Funakura M Kanai E, Watanabe Y. Effect of mental fatigue on the central nervous system: an electroencephalography study. Behav Brain Funct. 2012 Sep;8(1):48.

38 Craig A, Tran Y, Wijesuriya N, Nguyen H. Regional brain wave activity changes associated with fatigue. Psychophysiology. 2012 Apr;49(4):574-82.

39 Alvarez J, Meyer FL, Granoff DL, Lundy A. The effect of EEG biofeedback on reducing postcancer cognitive impairment. Integr Cancer Ther. 2013 Nov;12(6):475-87.

40 Le Bon O, Neu D, Berquin Y, Lanquart JP, Hoffmann R, Mairesse $\mathrm{O}$, et al. Ultra-slow delta power in chronic fatigue syndrome. Psychiatry Res. 2012 Dec;200(2-3):742-7. 
41 Butt Z, Lai JS, Rao D, Heinemann AW, Bill A, Cella D. Measurement of fatigue in cancer, stroke, and HIV using the Functional Assessment of Chronic Illness Therapy - Fatigue (FACIT-F) scale. J Psychosom Res. 2013 Jan;74(1):64-8.

42 Kosinski M, Gajria K, Fernandes AW, Cella D. Qualitative validation of the FACIT-fatigue scale in systemic lupus erythematosus. Lupus. 2013 Apr;22(5):422-30
43 Cohen S, Kamarck T, Mermelstein R. A global measure of perceived stress. J Health Soc Behav. 1983 Dec;24(4):385-96.

44 Golden-Kreutz DM, Browne MW, Frierson GM, Andersen BL. Assessing stress in cancer patients: a second-order factor analysis model for the Perceived Stress Scale. Assessment. 2004 Sep;11(3):216-23.

45 Kennedy S, Kiecolt-Glaser JK, Glaser R. Immunological consequences of acute and chronic stressors: mediating role of interpersonal relationships. Br J Med Psychol. 1988 Mar;61(Pt 1):77-85
46 Kiecolt-Glaser JK, Glaser R. Psychoneuroimmunology and cancer: fact or fiction? Eur J Cancer. 1999 Oct;35(11):1603-7.

47 Kirschbaum C, Pirke KM, Hellhammer DH. The 'Trier Social Stress Test'-a tool for investigating psychobiological stress responses in a laboratory setting. Neuropsychobiology. 1993;28(1-2):76-81. 